\title{
¿Quién soy yo? Repensando mi ser-estar trans «Laura: Ullupako-Dominatrix»
}

Quije suis ? Repenser mon être trans "Laura: Ullupako-Dominatrix "

Who Am I? Rethinking my trans identity «Laura: Ullupako-Dominatrix»

\section{Laura Libertad Álvarez Mollinedo}

\section{OpenEdition}

Journals

\section{Edición electrónica}

URL: http://journals.openedition.org/bifea/8077

DOI: $10.4000 /$ bifea. 8077

ISSN: 2076-5827

\section{Editor}

Institut Français d'Études Andines

\section{Edición impresa}

Fecha de publicación: 1 diciembre 2016

Paginación: 407-417

ISSN: 0303-7495

\section{Referencia electrónica}

Laura Libertad Álvarez Mollinedo, « ¿Quién soy yo? Repensando mi ser-estar trans «Laura: UllupakoDominatrix» », Bulletin de I'Institut français d'études andines [En línea], 45 (3) | 2016, Publicado el 08 diciembre 2016, consultado el 05 noviembre 2020. URL : http://journals.openedition.org/bifea/8077 ; DOI : https://doi.org/10.4000/bifea.8077

\section{c) $(7) \Theta$}

Les contenus du Bulletin de l'Institut français d'études andines sont mis à disposition selon les termes de la licence Creative Commons Attribution - Pas d'Utilisation Commerciale - Pas de Modification 4.0 International. 


\title{
¿Quién soy yo? Repensando mi ser-estar trans «Laura: Ullupako-Dominatrix»
}

\author{
Laura Libertad Álvarez Mollinedo*
}

\section{Resumen}

Escrito en primera persona, este ensayo presenta la trayectoria de Laura Álvarez desde su infancia, con una identidad social masculina, su desempeño como agrónoma, hasta su presente de mujer trans.

Palabras clave: autobiografía, transgénero, LGBT, Bolivia

\section{Qui je suis ? Repenser mon être trans « Laura: Ullupako-Dominatrix»}

\section{Résumé}

Écrit à la première personne, cet essai retrace la trajectoire de Laura Álvarez depuis son enfance sous une identité sociale masculine, puis son parcours en tant qu'agronome, jusqu'à son présent de femme trans.

Mots-clés : autobiographie, transgenre, LGBT, Bolivie

\section{Who Am I? Rethinking my trans identity «Laura: Ullupako-Dominatrix»}

\footnotetext{
Abstract

This first-person essay recounts the trajectory of Laura Alvarez from her childhood, with a masculine social identity, through her work as an agronomist, and continues up to her present life as a trans woman.

Keywords: Autobiography, transgender, LGBT, Bolivia

Activista boliviana de la población con diversa orientación sexual e identidad de género. E-mail: tranylaura@yahoo.es
} 
Mis genes memorísticos me llevan a la época, antes de la Guerra del Chaco, cuando mi abuelo, por parte de mi papá, trabajaba desde sus trece años para mantener a su madre (mi bisabuela) en las minas del sur de Potosí: Chorolque, Betillas, Siete Suyos, Ánimas, Santa Ana, Telamayu, Quechisla, Buen Retiro, Tasna, Cerdas, la zona que comprende desde los valles de Tupiza hasta Cotagaita, en el departamento de Potosí. Allá donde la uva, la manzana y la miel son manjares que se combinan con el estaño, el bismuto y la plata.

Mi bisabuelo, una persona de apellido Álvarez, abandonó a su esposa, una señora de pollera Ilamada Salustiana Romero, quien con tres hijos varones se vio sola y con dificultades para poder mantenerlos. Su hijo, mi abuelo Ángel Álvarez, el hermano mayor, nació en la población de Cotagaita, Potosí. Tuvo que trabajar desde sus once años cargando mineral; no tuvo infancia, no jugaba ni reía. A sus dieciocho años fue a la Guerra del Chaco con el Batallón de Infantería de los famosos «111», recibió una bala en la pierna, que nunca se quiso sacar, tuvo el grado de Sargento. Aprendió a leer y escribir a sus 37 años, estudió por correspondencia para ser Técnico Constructor en una escuela de Argentina.

En la población de Quechisla (centro administrativo de las minas del sur de Potosí durante la Corporación Minera de Bolivia-COMIBOL) conoció a Alejandrina Alfaro, una cholita muy tímida. Se casaron y tuvieron seis hijos: Moisés, Matilde, Abel, Esther, Elena y Mabel. Mi abuela pertenecía a un pueblito de ex hacienda llamado Chicorque, donde se produce maíz y se elabora chicha, a unos 50 kilómetros de las poblaciones de Atocha y Telamayu.

Mi abuelo Ángel nunca estuvo orgulloso del apellido Álvarez de su padre, pero tuvo que soportarlo por cuestiones de una paternidad ficticia y por la época en la que el apellido del padre pesaba más que el de la madre. A sus 45 años se fue a trabajar a Nicaragua (Centroamérica) por recomendación del gerente de la filial Quechisla de la COMIBOL. Se quedó dos años. Allá aprendió a trabajar de forma ordenada y disciplinada con los «gringos», como él mismo decía. A su retorno vino con la doctrina del adventismo, secta religiosa que espera la segunda venida de Cristo.

Nunca me habló de las costumbres y tradiciones de su lugar de nacimiento, sentía vergüenza, me decía que el quechua solo lo hablan los «indios», que para él no eran personas y que solamente servían para trabajar, tomar y emborracharse. Todos mis tíos y tías, también mi papá, fueron bautizados por la religión adventista. Además estudiaron en el Colegio Adventista de Bolivia, ubicado en la zona de Vinto en Cochabamba.

En 1969, nació su segundo nieto en La Paz, un 7 de septiembre a las 4 de la madrugada. Mi papá Abel, a los 22 años, conoció a una mujer llamada Leticia Mollinedo proveniente del Beni; se enamoró y nací yo. Ellos se separaron y nunca la conocí. Me criaron mis tías y mis abuelos. Nunca sentí la ausencia de mi mamá Leticia.

Desde mis cinco hasta mis seis años viví con mi abuela en el campo, en su comunidad. Ella era comerciante, compraba mercadería de la Quiaca-Villazón y Oruro, por lo que siempre estuve con ella; viajábamos en tren, en camión en 
flota. Fue en el campo donde aprendí a pastear ovejas y cabras, a ordeñarlas; también vi las relaciones de trabajo en comunidad, como el ayni, que es el trabajo agrícola realizado por todas las personas de la comunidad. Aprendí a comer el arrope (crema fermentada con chankaka, melaza de caña, para elaborar la chicha de maíz) y muchas otras costumbres que se quedaron en mi memoria histórica.

Luego fui criado como cualquier otro niño, desde el campo, las ciudades (Cochabamba y La Paz) y las minas (Catavi, Siglo XX, Telamayu, Quechisla, Chorolque y Santa Ana). Los viernes y sábados de cada semana teníamos que dedicarlos al «culto adventista», estaba prohibido escuchar radio, jugar, ver televisión y solamente orábamos o rezábamos, aprendíamos de memoria los versículos de la biblia y también cantábamos; incluía ir a la iglesia bien bañados y trajeados. Ahora ya no practico estas actividades y he olvidado aquellos versículos bíblicos.

Por otra parte, el trabajo en casa lo teníamos que realizar nosotros; mis abuelos nos decían que nunca nos pondrían empleada doméstica. Eso sí, en las minas vivimos en casas donde solamente viven los profesionales, ingenieros y doctores, casas grandes y suntuosas que teníamos que limpiarlas, lustrarlas y mantenerlas nosotros (mis primos y yo). Teníamos turnos para lavar los enceres, lustrar el piso, cocinar, atender a los animales domésticos (también criábamos gallinas, patos, pavos y conejos), cultivábamos papa, haba y arveja, nos ocupábamos de la siembra, el aporque, el riego y la cosecha. Los trabajos de mecánica, plomería y carpintería también los hacíamos nosotros, sin distinción alguna; el género era raro en mi familia, los roles no estuvieron delimitados.

Eso sí nunca nos hicieron faltar cariño, pero yo era el niño mimado, el niño que nació en una ciudad, me arrancaron del campo porque según ellos no estaba bien que me criaran allá, tenían otros planes para mí. Mi abuela Alejandrina veía en mí a un doctor, a un ingeniero, la idea del campesino era lo peor para mi familia. Sin embargo, desde mis 8 años me sentía bien cuando me colocaba las ropas de mis tías y mis primas; me «transformaba en una niña», accedía a las pinturas labiales de mis tías, a los corpiños y batas cuando nadie estaba en casa; también pasaba horas mirando cómo jugaban las niñas en la escuela, pero yo era el hombrecito, el niño mimado de la casa. Aquello que hacía no estaba bien, por eso Laura era clandestina, oculta, solamente yo sabía de mi otro yo. Mi familia en realidad crió a una niña y no quisieron percatarse de aquello. Alguna vez cuando conversaban mis abuelos en el idioma quechua, él le decía a mi abuela: «Este chiquito como mujercita no más es» (kay chi'ticito hurmicita jina y?) a lo que ella le respondía con una sonrisa.

Desde los 14 años viví en La Paz con la nueva familia de mi papá. Tuve una madrastra y tres hermanos. La madre de mi madrastra, una señora anarquista, me enseñó a ser rebelde y contestataria, ella perteneció a la FOLC (Federación Obrera Local), era dirigente del sindicato de culinarias. Su historia me impactó y me hice dirigente de la FES (Federación de Estudiantes de Secundaria). A mi papá no le gustaba aquello, él quería un hijo «normal y derechito», pero no está en mí ser así. También me volví rockero-metalero en la época de los ochenta con Wara, Luz de América, Los Jaivas, Papos Blues, Deep Purple, Scorpions, Led Zeppelin, 
Queen, Santa Ana, AC \& DC, etc. Leía a Kropotkin, Vakunin, Trotsky, Makarenko y otros, lo Disney nunca me cuadró y nunca me gustaron las telenovelas, prefería tocar zampoña y quena. Paralelamente practicaba atletismo, era muy bueno como corredor de medio fondo (media maratón) y jugaba basquetbol. Mi papá fue entrenador de la selección femenina de básquet que fue al mundial de SeúlCorea en 1980, también fue normalista de Educación Física en el Magisterio. No fui buen alumno, siempre entraba a desquite y tenía desacuerdos con los profesores. Luego ingresé al cuartel en Bajo Seguencoma en el comando general de la armada, no acabé porque el comandante me agredió físicamente y yo le respondí, me dieron una libreta militar de exención como inhábil. Serví ocho meses, encerrado aprendiendo a ser hombrecito y subordinado.

Laura se fue a estudiar agronomía a Cochabamba. Tardé siete años en egresar y hacer tesis; en esa época las confusiones calaban en mi cabeza, no me entendía ni como hombre ni como mujer, aquel hombre público estudiante y aquella mujer clandestina-oculta. Incluso cuestionaba mi corporalidad y me hice fisicoculturista; es más, salí campeón cochabambino en 80 kilos.

Hice la colegiatura de una maestría en Agroecología, Cultura y Desarrollo Sostenible, nunca quise ser el típico ingeniero agrónomo, con su hato lechero o su huerto de frutales. Elegí ir al campo en busca de mis ancestros y de mi cultura, lo que mis abuelos y mi familia me negaron. Trabajé trece años en áreas rurales, de cabecera de valle, puna y también el trópico de Cochabamba, bajo los principios de la observación participativa y el involucramiento con las personas del área rural; practicando la Pachasofía del pachankiri (ser-estar cotidiano) hasta la interrelación de aspectos como Humanidad-Naturaleza-Espiritualidad, donde los saberes locales saltan sobre la ciencia y aprendí a sentirla como otra forma de ver la vida.

Para comprender mejor esto de los saberes locales, me permito remitir a AGRUCO (Centro de Agroecología de la Universidad de Cochabamba). En este lugar pudimos reflexionar sobre un modo particular de entender el mundo, una manera específica de llamar a los acontecimientos y formas especiales de reproducir este saber, que es fundamentalmente intuitivo y basado en la praxis de una determinada cultura con la naturaleza.

En mi tesis sobre acceso al territorio en San Juan de la Comuna (Provincia Bolívar, departamento de Cochabamba) confirmé que son las mujeres las que acceden al territorio antes que los varones y son ellas las que eligen a los 16 años a sus parejas y pasan su primera fiesta. También pude ver muchas cosas que atestiguan que la sexualidad en el campo está ligada a lo territorial, a la ritualidad, a los movimientos poblacionales, a las ferias y a la producción agrícola y pecuaria. Una cholita en Tacopaya (Provincia Arque de Cochabamba) me dijo que quería casarse conmigo, pero nunca me dejaba decirle «te amo». La palabra amor no existe en el idioma quechua, mejor es la querencia (del verbo munay, querer); eso de hacer el amor no existe. El haber tenido un contacto sexual-genital en un camión mientras viajábamos, me hizo dar cuenta que en el campo no hay etiqueta, no es hacer el amor, simplemente es «culear» que en quechua es sump'ichir (hace alusión a 
tomarte por la cintura y penetrarte con fuerza); eso del misionero es solamente cuando estás en la cama. En una quebrada, en una cueva, tras un árbol o en el maizal o el habal, te acomodas como puedes.

Tuve la oportunidad de trabajar en Parotani, Cochabamba, donde se realizan las wallunk'as en la época de Todos Santos y donde el columpio (la wallunk'a) es solo para las cholitas jovencitas, para las sipakos (mujer joven), que en la antigüedad columpiaban sin calzones, para atrapar con los pies las canastas que contenían huevos (signo de fertilidad masculina). Es la cholita quien elige cómo y con quién tener relaciones sexuales, es la wallunk'a que la lleva a ser fertilizada.

En mi trabajo como consultor fui a trabajar a Rakhay Pampa, población también del departamento de Cochabamba, donde las relaciones sexuales-genitales son para los jóvenes que retornan del cuartel, donde la sífilis es tan común como las flores que allá se dan. Las «orgías» son comunes y los curanderos las promueven para controlar la enfermedad venérea, a modo de una vacuna como los actores externos la vemos: consultores, profesores, agrónomos, etc. «No hay preservativo», «no puedes vacunar con condones», nos decían. Yo fui parte de estas orgías y comprendí que los contactos sexuales no deberían limitarte y cuadrarte como algo solamente erótico, reproductivo y biológico. Va más allá, pasando por un fácil entender de que una enfermedad está en la mente y no en el cuerpo, así también las relaciones y contactos sexuales son parte del cuerpo y la mente. Que, en este caso, es el cuerpo comunal, la comunidad campesina.

En la comunidad de La Comuna (Provincia Bolívar, Cochabamba) donde hice mi trabajo de investigación de grado, me hablaron de las ullupakos (ullu=pene; sipako=mujer joven; en quechua), que son las mujeres con pene. Me mostraron incluso dibujos de hombres varones que tenían relaciones anales con las ullupakos a las que, según las awichas (abuelas), se las veía como cholitas machitos. Cuando la ullupako embarazaba a una mujer, era de buen augurio, significaba buen año con lluvias adelantadas y buenas cosechas. A nuestro buen ver, no eran otra cosa que las mujeres trans de la comunidad. Estos datos no los coloqué en mi tesis porque en ninguna de las variables de análisis contemplaba hablar de sexo y menos de género. En último caso estaría hablando de mí misma, de Laura, de la mujer con pene.

¿Qué comprende el ser normal? Viví una normalidad ajena a Laura como un varón incomprendido, no me aceptaba como mujer. Aquel hombre se casó con una mujer orureña de «buenas costumbres», conservadora y fiel. Mi matrimonio duró ocho años. Aquella mujer se casó con un hombre y no con una mujer, como en algún momento me lo dijo. Hace más de cuatro años que estoy «divorciada» legalmente, sin embargo es parte de mi historia que siempre recordaré con cariño.

Estoy repensando mi ser-estar porque, no solamente soy un SER, también ESTOY porque soy una persona cultural, social, emocional. El considerarme mujer trans identificada con lo quechua y ahora como una mujer-trans-dominatrix ${ }^{1}$ me hace

1 Dominatrix: ejercicio sexual comercial de la dominación; la que es insumisa, la que manda, la que humilla, la que esclaviza, la que somete al otro que generalmente es hombre. 
ESTAR aquí y hace repensarme histórica y culturalmente. En este momento, en este espacio-tiempo soy Laura la ullupako, la mujer con pene, en este entendido no soy normal; soy una trabajadora sexual y dominatrix, soy una mujer transgresora y hasta donde pueda rebelde e insumisa.

Olvidé mencionar que también hablo en quechua.

- Kunanri, imataq canqui a?, nisunqha chay profesores, chay abogados, chay doctores, psicólogos ninku, tukuy científicos...

- Noqa qani uj ulluwarmi, uj jatun warmi, tiyani jatun makis, jatun chakis, jatun ñuñus, tonqhorina kani...

- Ima kausayninkiri?

- Noqa kay k'uchito tiyakuni, pujllakuni kay runaswan.

- Qhari kanki i?

- Mana mana, ñoqa warmi kani, warmi ullupako jina...

- Ima sutiyki?

- Laura Libertad.

Traducción:

- Ahora, ¿tú, qué eres pues?, me dicen esos profesores, esos abogados, esos doctores, psicólogos dice que son, todos científicos...

- Yo soy una mujer con pene, una mujer grande, tengo manos grandes, pies grandes, tetas grandes y voz gruesa, tengo.

- ¿Para qué vives entonces?

- Yo aquí en este rinconcito sentada estoy, jugando con esta gente.

- Hombre eres ino?

- No, no, yo soy mujer, como una mujer joven con pene.

- ¿Cuál es tu nombre?

- Laura Libertad. 
¿Quién soy yo? Repensando mi ser-estar trans «Laura: Ullupako-Dominatrix»
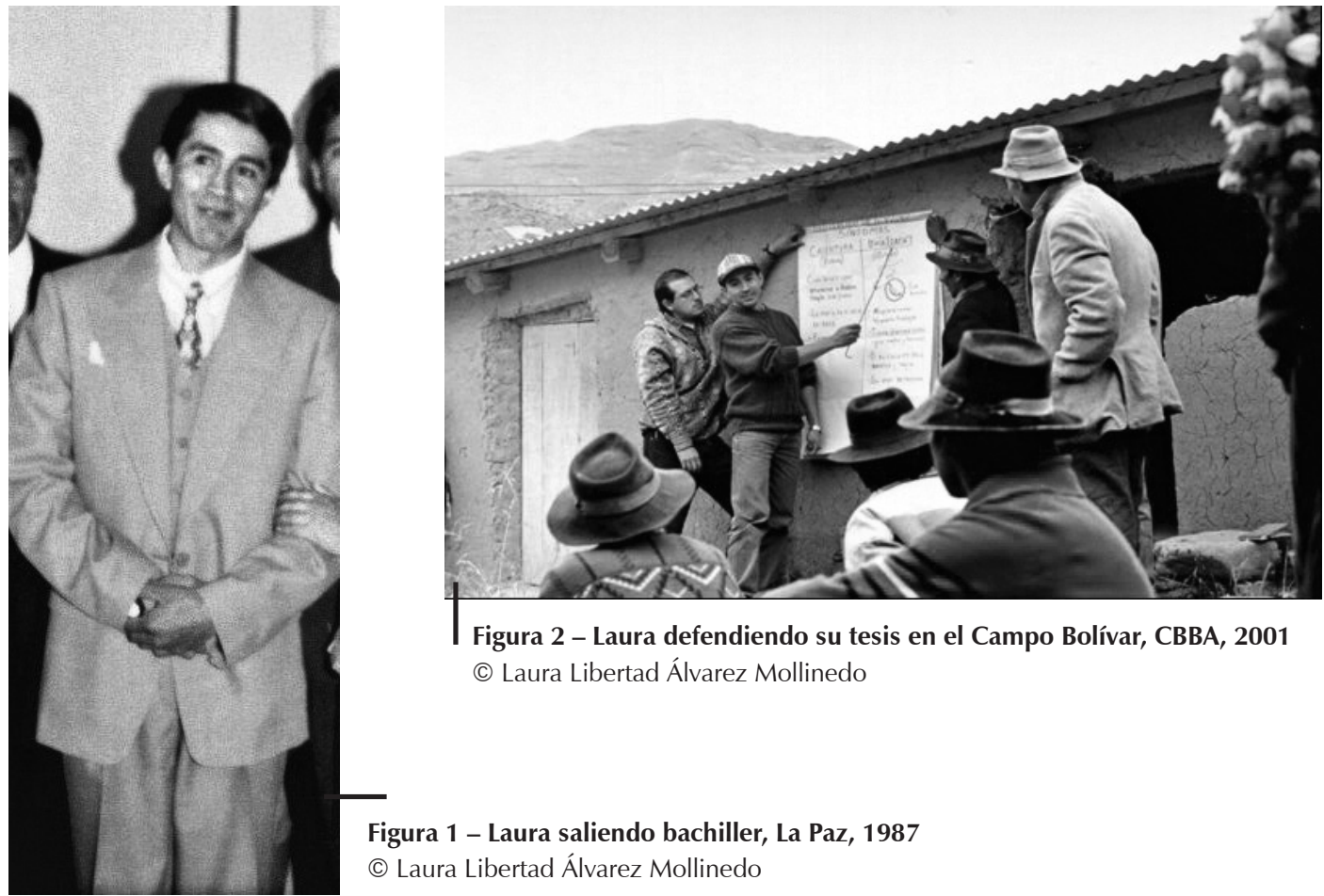

(C) Laura Libertad Álvarez Mollinedo

Figura 1 - Laura saliendo bachiller, La Paz, 1987

(C) Laura Libertad Álvarez Mollinedo

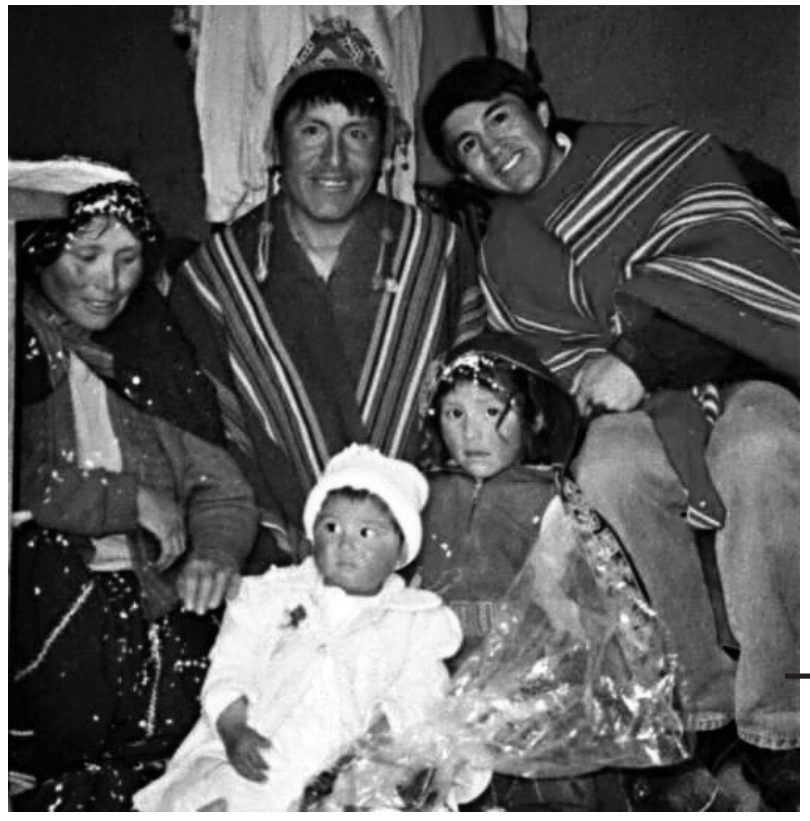

Figura 3 - Laura con sus compadres en el Campo Tapacarí, CBBA, 2002

(C) Laura Libertad Álvarez Mollinedo 


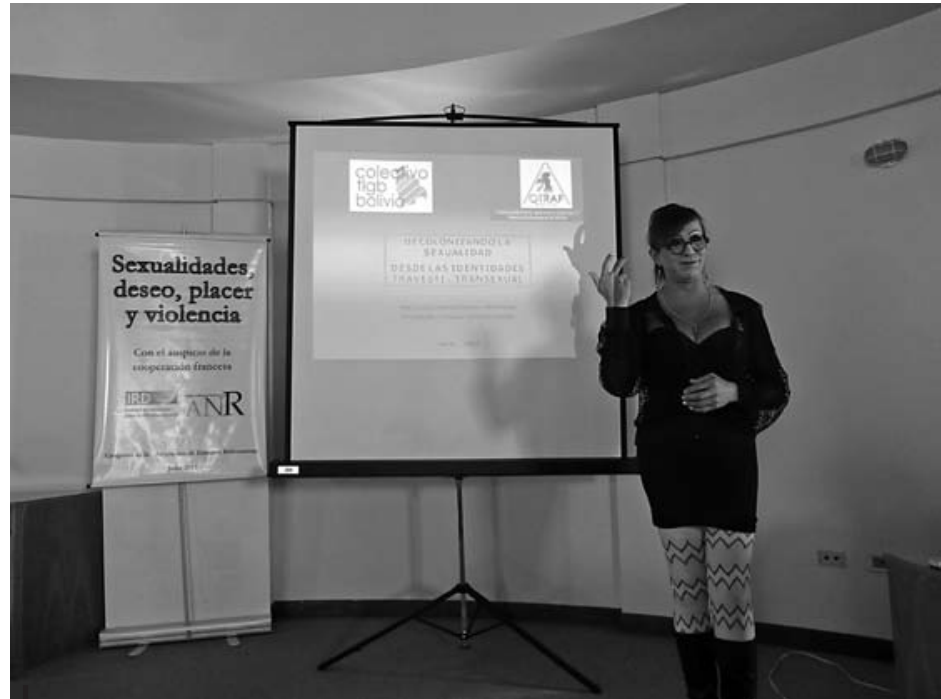

Figura 4 - Ponencia de Laura en el Coloquio «Sexualidades, deseo, placer y violencia»

VIII Congreso de la Asociación de Estudios Bolivianos, Sucre, julio de 2015

(C) Pascale Absi

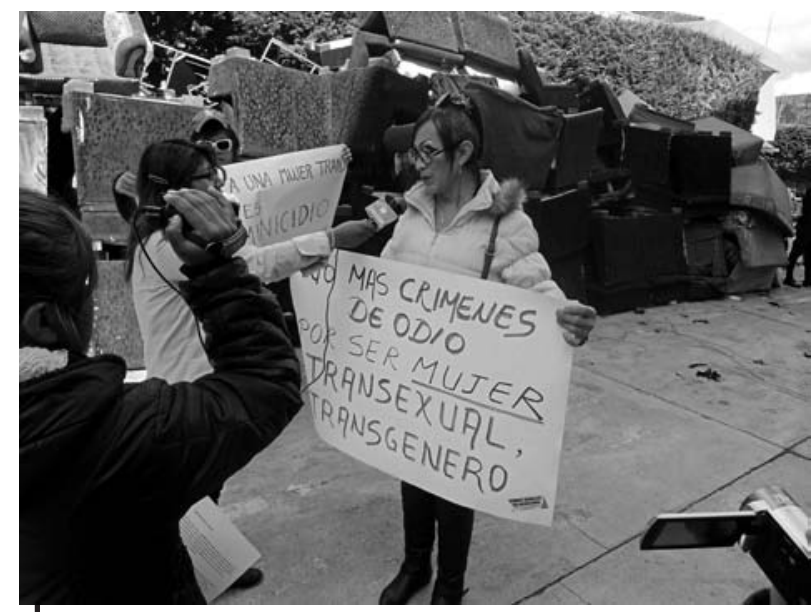

Figura 5 - Laura activista, La Paz, 2016

(C) Laura Libertad Álvarez Mollinedo

Figura 6 - Laura Dominatrix, 2016 (C) Laura Libertad Álvarez Mollinedo






\section{Anexo 1 - Yo decido sobre mi cuerpo, el Estado garantiza, la sociedad respeta y la psiquiatría no interviene}

Este texto es una edición recortada de la transcripción de la intervención de Laura Álvarez durante el simposio «Sexualidades, deseo, placer y violencia»².

El término «transexual» es un término médico, biologicista, esencialista. Tiene su sustento en estos famosos manuales de diagnóstico psiquiátrico como el DSM-V3, donde se cualifica como «disforia de género» el hecho de que lo biológico difiere de tu identidad de género interna. Decirle a cualquier grupo social que está enfermo es estigmatizarlo. Para hacer cualquier operación quirúrgica, ya sea de cambio de sexo genital, una cosa facial, hormonización, etc., muchos cirujanos dicen: «Primero haz tu evaluación psiquiátrica, mientras tanto yo no te voy a poder operar». Muchas de las mujeres trans no aceptamos que un psicólogo venga y diga «Ah, tú eres mujer» en base a un diagnóstico donde nos preguntan: «¿Tú siempre te vestías de mujercita? ¿Siempre te gustaba el color rosadito? ¿jugabas con soldaditos, con tanquecitos?». Luego viene el juez que sentencia, que ratifica si soy mujer o no. Es, pues, indigno y denigrante. Pero muchas otras mujeres trans sí se adecuan a esto para conseguir derechos. Voy a un psicólogo o a la psicóloga que me haga el diagnóstico de disforia de género para después yo acceder a derechos sanitarios, jurídicos... y acepto mi patología, acepto que estoy enferma. Es más, tengo compañeras que me dicen: «Ya estoy curada, ya soy mujer». Los protocolos de atención a las mujeres trans son otra herramienta de sujeción del poder y lo peor de todo es que la mujer trans se la cree. Pero nosotras no somos pacientes, somos sujetos activos con capacidad para decidir por nosotras mismas, rectificando la autonomía sobre nuestros cuerpos. Los doctores, los endocrinólogos, no saben tratar a las trans, les tratan de maricón o de lesbiana. Entonces la mayoría nos auto-recetamos hormonas con el riesgo de destrozarnos el hígado, los riñones, de hacer tiras nuestro cuerpo. Hay un sacrificio. Pero yo estoy viviendo como quiero ser. Yo decido sobre mi cuerpo, mi Estado garantiza, la sociedad respeta y la psiquiatría no interviene.

Por eso estamos proponiendo una ley de identidad de género que despatologice todo esto ${ }^{4}$. Desde otra visión, a partir de las ciencias sociales, se considera que la

2 VIII Congreso de la Asociación de Estudios Bolivianos, miércoles 22 y jueves 23 de julio de 2015, Sucre, Bolivia.

3 El quinto Diagnostic and Statistical Manual of Mental Disorders publicado en 2013 por la Asociación Estadounidense de Psiquiatría, que inspira la gestión médica del transgenerismo en muchos países. Antes calificada como «Trastorno de identidad sexual», la «Disforia de género» aparece también en la Clasificación Internacional de Enfermedades de la OMS.

4 Entre tanto, el 21 de mayo de 2015, el Estado boliviano promulgó la denominada «Ley de Identidad de Género» que autoriza el cambio de dato de sexo, de nombre y de imagen de las personas transgénero de la jurisdicción de los jueces. Antes el trámite era judicial, ahora es administrativo. Independientemente de que hayan o no modificado su apariencia corporal, los solicitantes acuden al Servicio de Registro Civil quien registra el cambio. El único requisito es la presentación de un certificado psicológico que acredita que la persona conoce y asume las implicaciones de su decisión. Antes, los tribunales recibían y trataban contadas solicitudes, largas, onerosas y con resultados inciertos. Hoy, por ley, la resolución administrativa no deberá tardar más de 15 días. 
esencia de la sexualidad no está en los genitales5. De ahí es que yo me he atrevido a autodeterminarme como una mujer con pene. Ahí es donde la sociedad se desentiende totalmente. Me dicen: «Laura, ¿qué es eso de mujer con pene? No hay eso. La biología no dicta eso». Entonces, ¿qué soy yo? No soy un fantasma, ni ningún imaginario... iaquí estoy! Y soy una mujer con pene. Es una realidad. Aquí es donde entramos las mujeres y los hombres trans para romper el binarismo hombre/mujer: un pene no hace a un hombre, ni la vagina hace a la mujer. Así como hay mujeres con pene, hay hombres con vagina, esta es nuestra vivencia. A mí no me van a camuflar, por eso yo salgo a la calle así como soy.

El trabajo sexual es una lacra pero no nos dejan otra... No todas las personas tienen la vocación de ser prostitutas, de ser putas... Pero formar pareja, una mujer trans con un hombre hetero, gay... es complicado. Claro, hay casos de mujeres trans que tienen parejas, ellas dicen con todo orgullo: «Yo tengo mi marido y me mantiene». Eso es lo peor. «Caramba, tantos años de lucha, de modificar tu cuerpo... para que andes de sumisa ante un hombre? ¿Para que te esté manteniendo? ¿Para que le estés esperando con el almuercito, la casa limpia y la cama bien tendida? iAl carajo toda tu lucha!». Entonces aunque nos digan que el trabajo sexual esclaviza, ahí está el deseo y el placer... Es uno de los espacios para la mujer trans donde practicamos nuestra sexualidad; es una realidad que hay que decir.

Yo siempre digo, «Métete con mi maquillaje, con mi peluca, con mi teñido, con mi bota, pero no te metas con mi placer sexual, ahí sí te gano. Te gano porque yo voy a sentir mi placer sexual como yo lo deseo y lo hago». También lo demuestro, lo pongo en fotos, lo pongo en artículos, en entrevistas. Por eso es que yo no me voy a hacer mutilar el pene, los testículos, porque voy a perder mi placer sexual. Y bueno, a lo que más le teme la sociedad, la sociedad machista, es que una mujer con pene penetre a un hombre heterosexual entre comillas. Que un hombre heterosexual casado, con hijos, militar, diputado, vaya y nos busque para esto... Aquí es donde rompemos el placer sexual clásico del conservador, juntando ser mujer con eyacular, o coger, porque nos hemos acostumbrado a que el ser mujer es solo ser pasiva, ique te cogen! Pero no es así. Había habido esta otra forma y tampoco lo enfermaremos pues, porque así estamos practicando este tipo de sexualidad... Por eso que a las trans siempre las van a ver pues, ajustadita, tentadora ino? Rara es la trans que va a salir así nomás, como una persona, vamos a decir normal entre comillas. Les gusta mostrarse pues. Tienen que hacer ejercicio de su cuerpo, de su deseo, de su erotismo y eso lo ven como enfermizo, como anormal. «iPor qué te vistes así Laura, por qué te maquillas así, por qué no eres normal?». «Ya está, no soy normal» y no debo perder el orgullo. Por eso es que nuestra gran marcha del TLGB6 se llama pues, por el orgullo, porque estamos orgullosos de ser entre comillas anormales. También desde la visión legal no soy normal, a pesar de que muchas de mis compañeras quieren ser

5 Véanse, por ejemplo, los trabajos de Judith Butler que demuestran que, al igual que el género, el sexo es una construcción social y cultural (Butler, 2001).

6 Transexuales, Transgéneros, Lesbianas, Gays y Bisexuales. 
normales, adscribirse a la normalidad, para poder estudiar, trabajar, hacer familia, todo. Incluso hay chicas que me dicen: «Yo, Laura, soy mujer y te lo demuestro». Se bajan los calzones y te demuestran una vagina, sacan sus documentos y te demuestran que son mujeres, y te dejan callada, muda, uhm... Pero yo les digo: «No, no eres mujer. Eres mujer trans y sigues siendo anormal». Pero no aceptan eso porque todos queremos ser normales. Es incómodo, pero esa incomodidad te da cierto ejercicio de poder, de reivindicar tus cosas. Somos pues anormales, desde esa visión de lucha, de reivindicación...

\section{Referencias citadas}

BUTLER, J., 2001 - El género en disputa. El feminismo y la subversión de la identidad, 316 pp.; Barcelona: Paidós. 